\title{
Mordida aberta: etiologia e relacionamento com hábitos deletérios
}

\author{
Open bite: etiology and relationship with deletary habits
}

\author{
Alexandre Ramos Braga $^{1^{*}} \bullet$ \\ ${ }^{1}$ Belo Horizonte, Minas Gerais, Brasil. *Autor para correspondência. E-mail: dr.alexandrebragamg@gmail.com
}

\begin{abstract}
Resumo: A mordida aberta pode ser definida como a presença de uma dimensão vertical negativa entre as bordas incisais dos dentes superiores e inferiores. A etiologia da mordida aberta está associada à genética, como hereditariedade e fatores ambientais, como hábitos de sucção, função e tamanho anormal da língua, respiração pela boca, padrão de crescimento vertical alterado e patologias congênitas ou adquiridas. A mordida aberta pode ser classificada em dentária, dentoalveolar e esquelética e levar o indivíduo a dificuldades na mastigação, deglutição e fonação criando condições desfavoráveis para o indivíduo em seu meio social inclusive psicologicamente. O tratamento é difícil e de pouca estabilidade e deve ser iniciado o mais rápido possível, aumentando as chances de sucesso.
\end{abstract}

Palavras-chave: mordida aberta, etiologia, tratamento, estabilidade.

\begin{abstract}
An open bite can be defined as the presence of a negative vertical dimension between the incisal edges of the upper and lower teeth. The etiology of the open bite is associated with genetics, such as heredity and environmental factors, such as sucking habits, abnormal tongue function and size, mouth breathing, altered vertical growth pattern and congenital or acquired pathologies. Open bite can be defined as dental, dentoalveolar and skeletal and lead the individual to difficulties in chewing, swallowing and phonation conditions creating unfavorable conditions for the individual in their social environment including psychologically. Treatment is difficult and of little stability and should be started as soon as possible, increasing the chances of success.
\end{abstract}

Keywords: open bite, etiology, treatment, stability.

\section{Introdução}

A mordida aberta pode ser definida como a presença de uma dimensão vertical negativa entre as bordas incisais dos dentes superiores e inferiores (Ngan \& Fields, 1997). Fatores como hábitos de suç̧ão, função ou tamanho anormal da língua, respiração oral, padrão de crescimento vertical e patologias congênitas ou adquiridas podem dar origem a desequilíbrios oclusais, causando maloclusões dentárias, incluindo mordida aberta.

As mordidas abertas podem ser classificadas em dentárias, dentoalveolares e esqueléticas. A anomalia quase sempre está relacionada a algum hábito pelo qual os dentes em infraoclusão eram mecanicamente impedidos de completar sua erupção. Consequentemente, isso envolverá um número variável de dentes de acordo com a influência exercida pelo agente causador (Siqueira, 2002)

O tratamento da mordida aberta torna-se muito difícil devido aos vários fatores envolvidos, que incluem hereditariedade e fatores ambientais. $\mathrm{O}$ fator hereditário pode contribuir para o padrão de crescimento vertical pré-determinado e fatores ambientais como tonsilas hipertróficas, respiração bucal, hábitos bucais deletérios, anquilose dentária e anormalidades no processo de erupção são determinantes no surgimento da má oclusão.

Pacientes com crescimento vertical excessivo ou síndrome da face longa estão entre os mais difíceis de serem tratados. Nesses pacientes, rotação no sentido horário da mandíbula, ângulo goníaco aberto, arcos estreitos, exposição excessiva dos dentes superiores e gengivas, mordida aberta e um ramo mandibular curto são comuns (Fields et al., 1984).

O tratamento da mordida aberta torna-se muito difícil devido aos vários fatores envolvidos, que incluem hereditariedade e fatores ambientais. $\mathrm{O}$ fator hereditário pode contribuir para o padrão de crescimento vertical pré-determinado e fatores ambientais como tonsilas hipertróficas, respiração bucal, hábitos bucais deletérios, anquilose dentária e anormalidades no processo de erupção são determinantes no surgimento da má oclusão. 
A reversão da mordida aberta anterior pode ser alcançada através das mais diversas terapias, que vão desde a instalação de aparelhos ortodônticos até a supressão de hábitos deletérios como sucção não nutritiva e interposição lingual, possibilitando o desenvolvimento dentoalveolar anterior sem interferências, sendo mais indicada nas fases da dentição decídua e mista (Carvalho et al., 2009).

Basicamente os tratamentos propostos nos casos de mordida aberta são: modificação de comportamento para eliminação de hábitos ou funções anormais, movimentação ortodôntica por intrusão e extrusão de molares de dentes anteriores e tratamento cirúrgico de bases ósseas. O tratamento é difícil e de pouca estabilidade. $\mathrm{O}$ objetivo deste estudo é relacionar a prevalência da mordida aberta com hábitos deletérios.

\section{Revisão}

Maciel e Leite (2005) realizaram um estudo buscando associar as disfunções orofaciais e os hábitos orais prejudiciais à mordida aberta anterior para um melhor entendimento da etiologia e desenvolvimento da mordida aberta. Foram adotados 130 alunos do ciclo básico da educação da cidade de Juiz de Fora-MG com idade média de 9 anos. A primeira etapa do estudo foi realizada por meio da coleta de dados por meio de questionário enviado aos responsáveis pelos hábitos orais e a segunda etapa por meio de exames odontológicos e fonoaudiológicos. A principal má oclusão identificada na amostra foi a mordida aberta anterior com sobreposição representando 33,8\% da amostra. Identificou-se associação entre o histórico de hábitos parafuncionais e a ocorrência de interposição lingual na deglutição e alteração fonoaudiológica.

Sousa et al. (2007) buscou avaliar a prevalência de mordida aberta na prótese decídua em pré-escolares da cidade de Natal/RN e sua associação com alguns fatores de risco. Foi realizado um estudo transversal com amostra de 366 crianças de 5 anos na fase de prótese total decídua. As informações foram coletadas por meio de um questionário que analisava variáveis socioeconômicas, demográficas e independentes como: tipo de aleitamento materno, duração do aleitamento materno exclusivo, tempo de aleitamento artificial, hábito e tempo de hábito. Houve diferença significativa de associação entre classe econômica, renda e presença de hábito. A prevalência de mordida aberta anterior foi de 20,6\% do total da amostra.

Zapata et al. (2010) verificou por meio de estudo a ocorrência de mordida aberta e hábitos orais deletérios em crianças de quatro a anos de idade. 266 crianças de quatro a seis anos, de ambos os sexos, na cidade de Suzano - São Paulo. As avaliações consistiram na aplicação de uma ficha de avaliação para detectar a ocorrência de hábitos orais prejudiciais aos responsáveis e na realização de um exame clínico composto por 13 avaliações da oclusão das crianças. Verificou-se que 221 crianças $(83,1 \%)$ apresentavam pelo menos um hábito oral nocivo, sendo o mais frequente o uso de mamadeira 167 (75,6\%). A ocorrência simultânea de hábitos nocivos e alterações na oclusão dentária foi observada em 119 crianças (44,1\% da amostra) e, nessas, a maior prevalência foi a presença da mordida aberta anterior, presente em 89 (79,8\%).

Mordidas abertas são classificadas como:

-Dentais: são aqueles que sofreram distúrbios na erupção dos dentes e no crescimento alveolar. Nesse tipo de má oclusão, os componentes esqueléticos do indivíduo são relativamente normais.

-Esquelético: são aqueles em que, além dos distúrbios dentoalveolares, existe uma desproporção entre os diferentes ossos que compõem o complexo craniofacial. Nesses casos, a mordida aberta é uma manifestação muito menos de uma discrepância séria. Os achados morfológicos mais frequentes encontrados neste tipo de anomalia incluem maior erupção dos incisivos superiores e molares. O pré-maxilar é girado para cima, e o plano que passa na borda da mandíbula é girado para baixo, e a mandíbula também pode estar retruída em relação à base do crânio. Esses fatores contribuem para um aumento vertical da face, principalmente da região ântero-inferior (Petrelli, 1992).

A mordida aberta apresenta os fatores etiológicos mais frequentes: hábitos deletérios, hábito de sugar chupeta ou dedo causando alteração da função da linguagem e consequentemente sua adaptação ao problema, crescimento vertical, como um distúrbio de erupção dentária associado a alveolar posterior crescimento da mandíbula e maxila, promovendo inclinação anterior do plano palatino com aumento da altura facial ânteroinferior, função muscular (Sodré et al., 1998).

O componente genético é o principal fator das mordidas abertas esqueléticas, pois seu desenvolvimento está diretamente relacionado ao padrão de crescimento facial do paciente. A presença de hábitos orais prejudiciais, deglutição atípica e respiração bucal podem aumentar a intensidade das mordidas abertas esqueléticas (Almeida et al., 2000).

Bueno et al. (2013), por meio de um estudo transversal observacional em crianças de 4 a 5 anos, verificaram a associação do aleitamento natural, uso de chupeta e clareamento nasal em relação à aparência e maloclusões 
em crianças. O uso de chupeta foi considerado um hábito deletério mais prejudicial, aumentando as chances de mordida aberta e enfatizando a importância da intervenção em crianças em idade pré-escolar.

O hábito de sugar sem fins nutricionais, devido à complacência generalizada, é bastante comum em nossa civilização, seja a sucção digital ou a chupeta. Esses hábitos podem gerar mudanças no desenvolvimento da oclusão, no crescimento, levando ao estabelecimento de maloclusões. Pode estar relacionado ao hábito de sucção digital: protrusão dos incisivos superiores, apinhamento ântero-inferior, diastemas ântero-superiores. No entanto, a má oclusão mais comumente vista é a mordida aberta anterior (Proffit, 2007).

A respiração bucal é um padrão respiratório que pode determinar alterações na posição dos dentes, mandíbula e língua, além da falta de selamento da cavidade oral pela ausência de contato entre os lábios, causando respostas neuromusculares indevidas para corrigir o crescimento e desenvolvimento craniofacial. Dependendo de sua duração, também pode causar alterações funcionais, estruturais, patológicas, posturais, oclusais e comportamentais (Emmerich, 2004).

Tibolla et al. (2012) verificaram por meio de estudo transversal da prevalência epidemiológica de mordida aberta anterior analisando o hábito de uso de chupeta e resultou em associação significativa entre uso e aparecimento de mordida aberta anterior. A frequência do hábito foi decisiva nesta associação nas dentições mista e decídua.

Os autores verificaram uma associação bem descrita entre hábitos nocivos e indivíduos com padrão de crescimento ósseo vertical e o aparecimento de Bite Open bite. O diagnóstico precoce favorece a autocorreção com a retirada do hábito, mas a dificuldade aumenta no tratamento em casa onde há crescimento vertical exacerbado.

Para um diagnóstico correto é essencial fazer um exame detalhado do paciente para elucidar as possíveis causas relacionadas ao problema. Verifique se de fato deve ser tratado, um problema emocional, respiratório, uma alteração funcional ou a combinação de todos os fatores (Almeida et al., 2006).

Crianças menores de 4 anos não devem sofrer interferência em seus hábitos de sucção, pois seu benefício emocional supera as possíveis perdas funcionais. Nesta fase, é importante que todos os fatores predisponentes à má oclusão sejam eliminados, mesmo que o problema ortodôntico não seja corrigido imediatamente. (Almeida et al., 1998).

A normalização da mordida aberta anterior que envolve as estruturas dentária e alveolar ocorre devido à musculatura peribucal, que produz alterações como a verticalização dos incisivos superiores e do processo dentário e alveolar (Silva Filho et al., 1995).

Matsumoto et al. (2012) enfatizou a dificuldade de tratar a mordida aberta. A complexidade dos fatores etiológicos é citada como o maior problema enfrentado pelos ortodontistas para garantir a estabilidade póstratamento. A precisão do diagnóstico e um plano de tratamento adequado são essenciais para finalizar o caso corretamente.

\section{Discussão}

Os fatores etiológicos da mordida aberta anterior podem ser divididos em fatores genéticos que estão diretamente relacionados ao padrão de crescimento vertical do paciente e fatores ambientais como chupeta ou hábito de sucção de dedo, interposição lingual e distúrbios de erupção dentária causando alterações no crescimento facial e distúrbios musculares. Os autores pesquisados convergem para a associação entre hábitos deletérios e padrão facial vertical com a causa da mordida aberta anterior (Sodré et al., 1998).

Zuanon et al. (2000) enfatizou que os hábitos orais prejudiciais causam lesões estruturais na cavidade oral, causando desequilíbrios musculares entre bochecha, lábio e língua, causando a mordida aberta anterior mais frequente.

Proffit em 2007 relatou que hábitos de sucção não nutritivos têm grande aceitação em nossa civilização. Esses hábitos podem gerar mudanças causando maloclusões. Na fase de crescimento, esses hábitos tornamse ainda mais prejudiciais, pois interferem no desenvolvimento. O hábito mais comum é a sucção digital causando várias alterações como apinhamento, diastemas, mas a má oclusão mais comum é a mordida aberta anterior.

A respiração pode causar alterações na posição dentária e pressão inadequada de massa muscular no esqueleto estando associada ao aparecimento de mordida aberta anterior. Os autores relatam que a respiração oral interfere na posição da língua em repouso e na ação. A posição da língua sobre os incisivos apoiados entre as bordas dos incisivos superiores e inferiores pode causar uma proporção bitelar grande e de difícil tratamento (Proffit, 2002). 
Bueno et al. (2013) consideraram o uso de chupeta como os hábitos deletérios mais prejudiciais. O tempo de uso da chupeta é um fator determinante para o aparecimento de más oclusões, exigindo um plano de tratamento já em andamento nas crianças em idade pré-escolar.

Em Jabur (1999) relacionou a deglutição atípica com uma mordida aberta anterior. A falta de espaço favorece o posicionamento ideal da língua, ocasionando um posicionamento em direção à abertura da cavidade oral. A pressão feita pela língua para obter espaço causa a mordida aberta anterior.

A presença de fatores ambientais como causa exclusiva está mais presente na mordida dentoalveolar aberta. Quando há um grande comprometimento, fatores genéticos esqueléticos são associados e o padrão vertical aparece como predominante (Torres et al., 2006).

O diagnóstico precoce parece ser preponderante para um tratamento satisfatório, e sua dificuldade parece ser a causa do insucesso de alguns tratamentos que deveriam ser multidisciplinares. A retirada dos hábitos de sucção não deve ser feita antes dos 4 anos de idade, pois o benefício emocional desse hábito é mais interessante neste momento da vida nas alterações funcionais causadas. Almeida et al. (1998) preconiza a retirada dos elementos que predispõe mesmo sem a correção total da mordida aberta.

A normalização da função da musculatura, língua e outras estruturas orais pode corrigir a mordida dentoalveolar anterior aberta pelos incisivos e extrusão dos processos alveolares. Aparelhos ortopédicos como o Bionator Fechado são grandes aliados nesse processo.

Os autores convergem para o tratamento multidisciplinar, sendo necessário acompanhamento fonoaudiológico para melhoria dos resultados e verificação da avaliação de mudanças que prejudiquem o tratamento. Marchesan (1998) descreveu a interferência da respiração oral no crescimento e, consequentemente, o aparecimento de uma mordida aberta justificando o acompanhamento do otorrinolaringologista.

\section{Considerações finais}

A mordida aberta anterior é uma má oclusão de difícil tratamento devido à diversidade e complexidade de seus fatores etiológicos. Fatores genéticos, como padrão de crescimento ósseo, e fatores ambientais, como hábitos orais prejudiciais, são as principais causas. O padrão de crescimento vertical e hábitos orais deletérios quando associados aumentam a dificuldade do tratamento. O diagnóstico preciso e precoce favorece o planejamento correto e o sucesso do tratamento. O envolvimento de diversos profissionais como médicos, fonoaudiólogos e psicólogos é fundamental quando se detecta algum comprometimento nessas áreas. É necessário observar atentamente os pais e responsáveis quanto ao aparecimento e procurar tratamento o mais rápido possível.

\section{Referências}

Almeida, M. R., de Almeida, R. R., Conti, A. C. D. C. F., de Lima Navarro, R., de Oliveira Correa, G., de Oliveira, C. A., \& Oltramari, P. V. P. 2006. Estabilidade a longo prazo do tratamento da mordida aberta anterior na dentadura mista: relato de caso clínico. Journal of Applied Oral Science, 14(6), 470-475.

Almeida, R. R., Pedrim, R. R. A., Almeida, M. R., Garib, D. G., Almeida, P. C. M. R., \& Pinzan, A. 2000. Etiologia das más oclusões - causas hereditárias e congênitas, adquiridas gerais, locais e proximais (hábitos bucais). Revista Dental Press de Ortodontia e Ortopedia facial, 5(6), 107-129.

Almeida, R. R., Santos, S. C. B. N., Santos, E. C. A., Insabralde, C. M., \& Almeida, M. R. 1998. Mordida aberta anterior - considerações e apresentação de um caso clínico. Revista Dental Press de Ortodontia e Ortopedia facial, 3(2), 17-29.

Bueno, S.B. et al. Association of breastfeeding, pacifier use, breathing pattern and malocclusions in preschoolers. Dental Press J Orthod, v.18, n.30, p.1-6. Jan-Feb, 2013

Carvalho, C. M., Carvalho, L. F. P. C., Forte, F. D. S., Aragão, M. S., \& Costa, L. J. 2009. Prevalência da mordida aberta anterior em crianças de 3 a 5 anos. Pesquisa Brasileira em Odontopediatria e Clinica Integrada, 9(2), 205-210.

Emmerich, A., Fonseca, L., Elias, A. M., \& Medeiros, U. V. D. 2004. Relação entre hábitos bucais, alterações oronasofaringianas e mal-oclusões em pré-escolares de Vitória, Espírito Santo, Brasil. Cadernos de Saúde Pública, 20, 689-697. 
Fields, H. W., Proffit, W. R., Philips, C., \& Stanek, E. 1984. Facial pattern differences in long-faced children and adults. American Journal of Orthodontics, 85(4), 217-223.

Jabur, L. B., Macedo, A. M., Cravero, L. H., \& Nunes, M. M. 1997. Estudo clínico da correlaçäo entre padräo respiratório e alteraçöes ortodônticas e miofuncionais. Revista Odontologia UNICID, 105-17.

Maciel, C. T. V., \& Leite, I. C. G. 2005. Aspectos etiológicos da mordida aberta anterior e suas implicações nas funções orofaciais. Pró-Fono Revista de Atualização Científica, 17(3), 293-302.

Marchesan, I. Q. 1998. Fundamentos em Fonoaudiologia: aspectos clínicos da motricidade oral. Rio de Janeiro, RJ: Guanabara Koogan.

Matsumoto, M. A. N., Romano, F. L., Ferreira, J. T. L., \& Valério, R. A. (2012). Open bite: diagnosis, treatment and stability. Brazilian Dental Journal, 23(6), 768-778.

Ngan, P., \& Fields, H. W. 1997. Open bite: a review of etiology and management. Pediatric Dentistry, 19(2), 91-98.

Proffit, W. R. 2002. Ortodontia contemporânea (3a ed.). Rio de Janeiro, RJ: Guanabara Koogan.

Proffit, W. R., Fields, H. W., \& Sarver, D. M. 2007. Ortodontia contemporânea (4a ed.). Rio de Janeiro, RJ: Elsevier.

Silva Filho, O. G., Chaves, A. S. M., \& Almeida, R. R. 1995. Efeitos terapêuticos suscitados pelo uso da classe palatina: um estudo cefalométrico. Revista da Sociedade Paranaense de Ortodontia, 1(1), 9-15.

Siqueira, D. F. 2002. Estudo comparativo, por meio de análise cefalométrica em norma frontal, dos efeitos dentoesqueléticos produzidos por três tipos de expansores palatinos. Tese de Doutorado. São Paulo, SP: Universidade de São Paulo.

Sodré, A. S., Franco, E. A., \& Monteiro, D. F. 1998. Mordida aberta anterior. Jornal Brasileiro de Ortodontia e Ortopedia Facial, 80-94.

Sousa, R. L. D. S., Lima, R. B. D., Florêncio Filho, C., Lima, K. C. D., \& Diógenes, A. M. D. N. 2007. Prevalência e fatores de risco da mordida aberta anterior na dentadura decídua completa em pré-escolares na cidade de Natal/RN. Revista Dental Press de Ortodontia e Ortopedia Facial, 12(2), 129-138.

Torres, F., Almeida, R. R., De Almeida, M. R., Almeida-Pedrin, R. R., Pedrin, F., \& Henriques, J. F. 2006. Anterior open bite treated with a palatal crib and high-pull chin cup therapy. A prospective randomized study. The European Journal of Orthodontics, 28(6), 610-617.

Zapata, M., Bachiega, J. C., Marangoni, A. F., Jeremias, J. E. M., Ferrari, R. A. M., Bussadori, S. K., \& Santos, E. M. 2010. Ocorrência de mordida aberta anterior e hábitos bucais deletérios em crianças de 4 a 6 anos. Revista CEFAC, 12(2), 267-271.

Zuanon, A. C. C., Oliveira, M. D. F., Giro, E. M. A., \& Maia, J. P. 2000. Relação entre hábito bucal e maloclusão na dentadura decídua. Jornal Brasileiro de Odontopediatria \& Odontologia do Bebê, 104-8.

\section{Minicurrículo}

Alexandre Ramos Braga. Possui graduação em Odontologia pelo Centro Universitário Newton Paiva. Especialização em Ortodontia pela FACSETE, e em Saúde Coletiva e Odontologia do Trabalho pela Faculdade Unyleya. Professor Tutor/Conteúdista da Faculdade Unyleya

Como citar: Braga, A.R. 2021. Mordida aberta: etiologia e relacionamento com hábitos deletários. Pubsaúde, 5, a088. DOI: https://dx.doi.org/10.31533/pubsaude5.a088

Recebido: 17 out. 2020.

Revisado e aceito: 3 nov. 2021.

Conflito de interesse: os autores declaram, em relação aos produtos e companhias descritos nesse artigo, não ter interesses associativos, comerciais, de propriedade ou financeiros que representem conflito de interesse.

Licenciamento: Este artigo é publicado na modalidade Acesso Aberto sob a licença Creative Commons Atribuição 4.0 (CC-BY 4.0). 